\title{
Trends of COVID 19 Vaccines: International Collaboration and Visualized Analysis
}

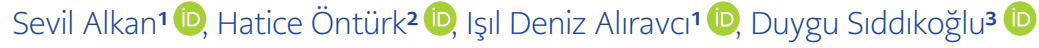 \\ 1 Department of Infectious Diseases and Clinical Microbiology, Çanakkale Onsekiz Mart University School of Medicine, Çanakkale, Turkey \\ 2 Nursing Department, Bitlis Eren University School of Health Sciences, Bitlis, Turkey \\ 3 Department of Biostatistics, Çanakkale Onsekiz Mart University Faculty of Medicine, Çanakkale, Turkey
}

\begin{abstract}
Objective: We aimed to evaluate the research and publication trends on the coronavirus disease (COVID-19) vaccine, and so guide future studies.

Materials and Methods: A bibliometric analysis was performed using a VOSviewer visualization methodology. Information about publications Web of Science database outputs, countries, institutions, journals, keywords, and citation counts was retrieved.

Results: A total of 929 eligible publications from January 1, 2020, to February 28, 2021, were derived from the WOS database according to the search criteria. Publications were written in nine languages, mainly in English (96.7\%). From these results, a total of 300 articles were reached by filtering. The average number of citations was found to be 7.73 . The $\mathrm{H}$-index of the articles, which were cited 2320 times in total, was 22. Most of the publications were articles (32.29\%) and editorials (28.09\%). There were 73 different research areas, mostly in general internal medicine (26.6\%) and immunology (19.05\%). The United States of America produced the majority of articles (31.32\%).

Conclusion: This bibliometric analysis presents that publications on the COVID-19 vaccine are rapidly changing at a time when exactly the effective vaccines of COVID-19 have not been discovered yet.
\end{abstract}

Keywords: COVID-19, vaccine, bibliometric analysis, VOSviewer, Web of Science

\section{INTRODUCTION}

oronavirus disease 2019 (COVID-19) was declined as a pandemic by the World Health Organization (WHO) in March 2020. The initial diagnosis of the disease was made in a very complex process. In addition to treating and preventing its spread, vaccination studies have been started rapidly (1). Since January 24, 2020, the University of Queensland in Australia started the COVID-19 vaccine development study, many vaccine studies, including our country, continue globally $(1,2)$. In February 2020, the WHO announced that it does not expect a vaccine against SARS-CoV-2 to be available in less than 18 months (3).

\section{Corresponding Author: Sevil Alkan \\ E-mail: \\ sevil3910@gmail.com}

Received: July 30, 2021 Accepted: October 6, 2021 Published: December 30, 2021

\section{Suggested citation:}

Alkan-Çeviker S, Öntürk H, Alıravcı ID, Sıddıkoğlu D. Trends of COVID 19 vaccines: International collaboration and visualized analysis. Infect Dis Clin Microbiol 2021; 3: 129-136.

DOI: 10.36519/idcm.2021.70 
Continuation of the pandemic without slowing down, increasing mortality and morbidity rates led to the global application of rapid vaccination $(1,2)$. The United States Food and Drug Administration (FDA) approved the emergency use of the vaccine on December 11, while the European Medicines Agency (EMA) approved its use in member countries on December 21. The Pfizer-BioNTech vaccine was first administered in England on December 8, New York on December 14, and European countries on December 27. As of December 27, 2020, 4231 vaccine candidates were still under development in European countries (4). By the time April 8, 2021, there were 231 ongoing vaccine studies (5).

With the declaration of COVID-19 as a pandemic, the state of global panic was also reflected in this scientific literature. Many articles from all fields related to COVID-19 began to be published globally; some were related to the vaccine even though there was not a COVID-19 vaccine yet. We aimed to evaluate how the developments on COVID-19 vaccines were reflected in scientific publications.

Data were retrieved from the Science Citation Index-Expanded (SCI-E) of the Web of Science (WOS) database (6). In addition, comprehensive bibliometric data and the SCI-Expanded, SSCI, A\&HCI, and ESCI citation index database were retrieved from the Web of Science (WOS) Core Collection, which is considered as the optimum database for bibliometrics (7).

\section{Search Strategy}

The dataset from January 1, 2020, to February 28, 2021, was obtained from the WOS Core Collection. The selected keywords to be used in the WOS search

\section{HIGHLIGHTS}

- The publications on the COVID-19 vaccine are increasing rapidly globally.

- The United States of America ranked in the first place about for publications on the COVID-19 vaccine.

- The publications on the COVID-19 vaccine have high citing rates. engine were "Corona OR Corona virus OR Coronavirus OR COVID-19 OR COV OR nCOV OR SARS OR SARS-COV-2' and 'vaccine OR vaccination'. In addition, "Language = English AND Document type = All" were included in the study. The information about publications, including research orientation, institutions, and funding, was ameliorated by the data in the WOS.

\section{Data Collection}

The titles, years of publication, names of authors, nationalities, affiliations, keywords, names of publishing journals, abstracts of each record, and citations within the publications downloaded from WOS, were saved as TXT files and imported into Microsoft Office Excel 2019 (Los Angeles, CA, USA). We used Çanakkale Onsekiz Mart University's online library and digital resources to access information.

\section{Bibliometric and Visualized Analysis}

The bibliometric analysis takes advantage of bibliometric theory to analyze pertinent literature through mathematical and statistical approaches, which has become an important tool for global analysis and investigation in various scientific areas $(8,9)$.

Basic characteristics of eligible publications, which were mentioned previously, were described through the intrinsic function of WOS. The Hirsch (H)-index was regarded as an optimum measurement to evaluate the impact of scientific research and was proposed as an alternative to other bibliometric indicators (10).

The H-index and the impact factor (IF) of the publishing journal were considered indicators of the impact of publications $(8,11)$.

\section{Analytical Methods}

Retrieved data were analyzed to present various bibliometric indicators, while maps were visualized using the visualization of similarities (VOS) viewer technique. We used VOSviewer (version 1.6.16; Leiden University Center for Science and Technology Studies, Leiden, Netherlands) for the visualized analysis of the publications, including bibliographic coupling, co-authorship, co-citation, and co-occurrence analysis $(8,9,11)$. 


\section{Ethical Consideration}

No ethical approval was required in bibliometric type studies as there is no human and animal involvement.

\section{RESULTS}

\section{Analysis of Global Publications}

According to the search criteria, a total of 929 eligible publications from January 1, 2020, to February 28, 2021, were derived from the WOS database. Publications were written in nine languages, mainly in English (96.7\%).

\section{H-Index Numbers}

The average number of citations of these 929 publications was found to be 5.99. The H-index was found to be 33, which were cited 5568 times totally.

\section{Citation Numbers}

From these results, a total of 300 articles were reached by filtering. The average number of citations for the articles was found to be 7.73. The $\mathrm{H}$-index of these articles, which were cited 2320 times in total, was 22.

\section{Publications Features}

When we examined the features of the publications, we found that the most were articles (32.29\%) and editorials (28.09\%) (Table 1).

According to the examination of research areas, there were 73 different areas, mostly in general internal medicine (26.6\%) and immunology (19.05\%). The main research areas of publications are given in Table 2.

Publications were from 97 different countries. The United States of America produced the majority of articles (31.32\%), followed by the United Kingdom $(9.90 \%)$ and India (8.93\%). Fifteen countries with the highest number of publications are given in Table 3.

The WHO was the most cited author (Table 4). Vaccine, The Lancet, and The New England Journal of Medicine were the most cited journals; total link strength (TLS) was listed accordingly (Table 5). The USA was cited 2090, China 1032, Norway 653, En-
Table 1. Types of documents.

\begin{tabular}{|l|c|}
\hline & $\mathrm{n}=929(\%)$ \\
\hline Original Article & $300(32.29)$ \\
\hline Editorial & $261(28.09)$ \\
\hline Review & $145(15.60)$ \\
\hline News item & $128(13.77)$ \\
\hline Early access & $91(9.79)$ \\
\hline Letter & $79(8.50)$ \\
\hline Other & $18(1.93)$ \\
\hline
\end{tabular}

Table 2. Research domain of documents.

\begin{tabular}{|l|c|}
\hline & $\mathrm{n}=929(\%)$ \\
\hline General internal medicine & $247(26.58)$ \\
\hline Immunology & $17(19.05)$ \\
\hline Research experimental medicine & $108(11.62)$ \\
\hline Science \& technology - Other topics & $84(9.04)$ \\
\hline Public, environmental and occupational & $68(7.32)$ \\
\hline health & $62(6.67)$ \\
\hline Pharmacy and pharmacology & $61(6.56)$ \\
\hline Applied microbiology and biotechnology & $41(4.41)$ \\
\hline Infectious diseases & $37(3.98)$ \\
\hline Microbiology & $35(3.76)$ \\
\hline Chemistry & $29(3.12)$ \\
\hline Biochemistry and molecular biology & $26(2.79)$ \\
\hline Pediatrics & $24(2.58)$ \\
\hline Healthcare sciences \& services & $22(2.36)$ \\
\hline Virology & $19(2.04)$ \\
\hline Engineering & \\
\hline
\end{tabular}

gland 522, and Thailand 433 times. The bigger the rectangle, the more citation the country has. There are four clusters formed; red color indicates cluster 1 (90 sources), green color indicates cluster 2 (57 sources), the blue color indicates cluster 3 (31 sources), yellow color represents cluster 4 (21 sources) (Figure 1, 2). 
Table 3. Summary of the highest number of publications according to countries.

\begin{tabular}{|l|c|}
\hline Countries/Regions & $\mathrm{n}=929(\%)$ \\
\hline USA & $291(31.32)$ \\
\hline England & $92(9.90)$ \\
\hline India & $83(8.93)$ \\
\hline $\begin{array}{l}\text { The People's Republic } \\
\text { of China }\end{array}$ & $71(7.64)$ \\
\hline Italy & $46(4.95)$ \\
\hline Germany & $43(4.63)$ \\
\hline Canada & $39(4.20)$ \\
\hline Australia & $33(3.55)$ \\
\hline Saudi Arabia & $22(2.37)$ \\
\hline Switzerland & $22(2.37)$ \\
\hline Turkey & $22(2.37)$ \\
\hline France & $19(2.05$ \\
\hline Netherlands & $19(2.05)$ \\
\hline South Africa & $19(2.05)$ \\
\hline Iran & $17(1.83)$ \\
\hline
\end{tabular}

Table 4. Top 15 cited authors.

\begin{tabular}{|l|c|c|}
\hline Author & Citations & $\begin{array}{c}\text { Total link } \\
\text { strength }\end{array}$ \\
\hline World Health Organization & 528 & 5345 \\
\hline Zhu, FC & 119 & 2074 \\
\hline Du, LY & 100 & 2375 \\
\hline Folegatti, PM & 94 & 1601 \\
\hline Centers for Disease Control & 88 & 467 \\
\hline and Prevention & 82 & 1354 \\
\hline Huang, CL & 82 & 1579 \\
\hline Jiang, SB & 79 & 963 \\
\hline Le, TT & 73 & 1330 \\
\hline Walls, AC & 72 & 1211 \\
\hline Zhou, P & 71 & 1238 \\
\hline Wu, F & 70 & 756 \\
\hline Lurie, N & 66 & 1033 \\
\hline Jackson, LA & 66 & 413 \\
\hline Mahase, E & & \\
\hline
\end{tabular}

Table 5. Top 15 journals with the most citations.

\begin{tabular}{|c|c|c|}
\hline Source & Citations & $\begin{array}{l}\text { Total link } \\
\text { strength }\end{array}$ \\
\hline Vaccine & 1027 & 45,895 \\
\hline The Lancet & 942 & 46,597 \\
\hline $\begin{array}{l}\text { The New England Journal } \\
\text { of Medicine }\end{array}$ & 775 & 40,280 \\
\hline Nature & 766 & 45,241 \\
\hline Science & 714 & 40,983 \\
\hline Journal of Virology & 612 & 48,055 \\
\hline $\begin{array}{l}\text { JAMA The Journal of the American } \\
\text { Medical Association }\end{array}$ & 437 & 17,113 \\
\hline $\begin{array}{l}\text { Proceedings of the National } \\
\text { Academy of Sciences }\end{array}$ & 378 & 24,823 \\
\hline Cell & 350 & 23,546 \\
\hline Plos One & 335 & 18,521 \\
\hline The Lancet Infectious Diseases & 294 & 16,782 \\
\hline The Journal of Infectious Diseases & 263 & 14,772 \\
\hline $\begin{array}{l}\text { Human Vaccines \& } \\
\text { Immunotherapeutics }\end{array}$ & 262 & 13,749 \\
\hline Journal of Medical Virology & 258 & 15,885 \\
\hline British Medical Journal & 250 & 6863 \\
\hline
\end{tabular}

The minimum number of citations of a source was set at 20. Of the total sources, only 217 sources meet the threshold. The Journal of Virology was the leading source with highest total link strength (TLS) 99,906 (citations $=1305)$, followed by Vaccine (TLS = 79,988, citations $=1369$ ), and Nature (TLS $=77,098$, citations $=1167)$. Huang $\mathrm{Cl}$ (82 times), Zhou P (71 times) and Le TT (69 times) were the most cited authors. Larger circles have slightly more references. The co-citation and cited sources visualization map is presented in Figure 3 and Figure 4.

\section{DISCUSSION}

Since COVID-19 was declared a pandemic, the rapidly increasing number of cases also accelerated vaccine development work. Results provide a comprehensive overview of the COVID -19 pandemic in the 46 countries leading in research.

Many databases such as; EBSCO, Scopus, Pro-Quest, PubMed, Science Direct can be used for bibliomet- 


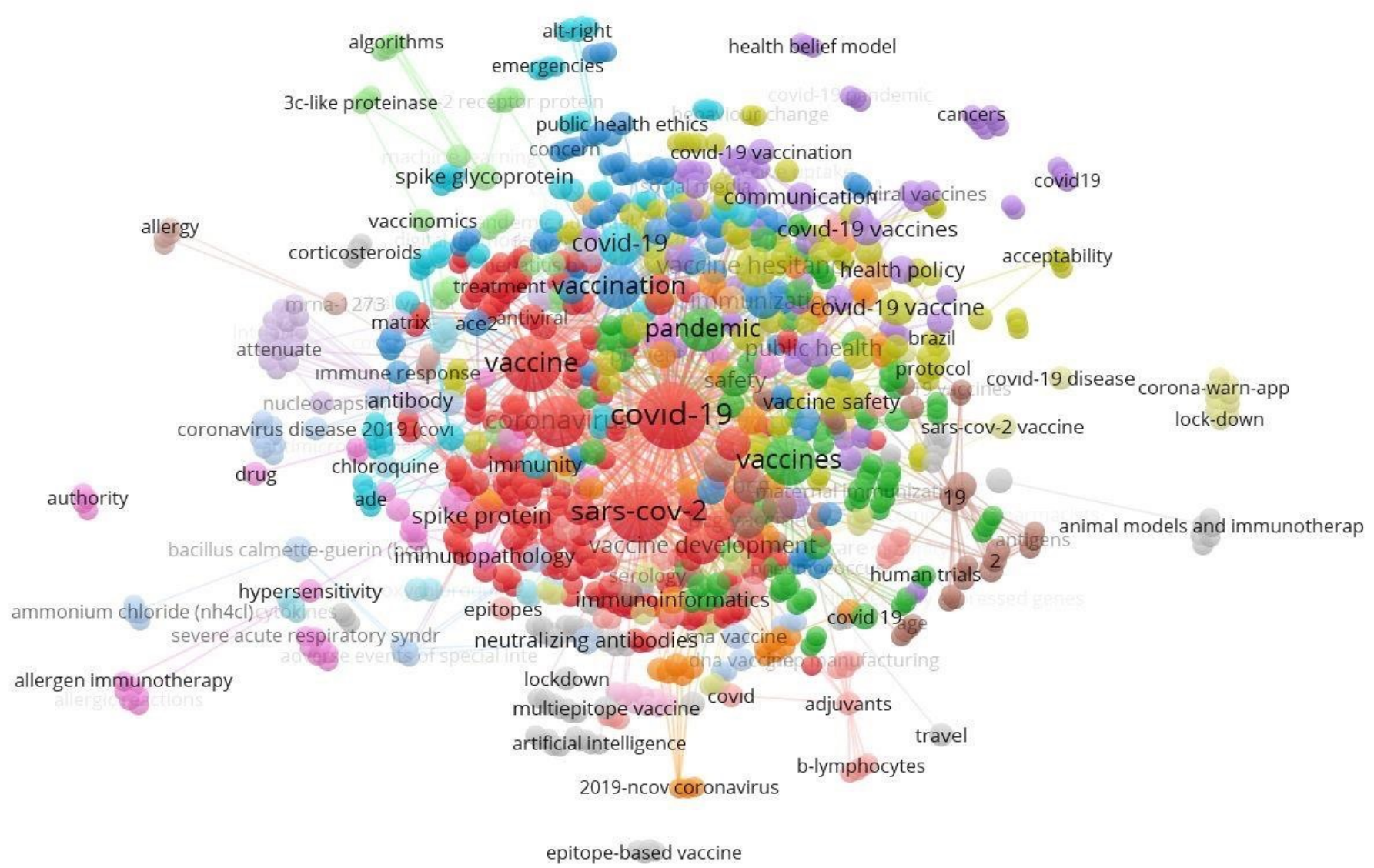

Figure 1. The density map of the keywords of the publications that are repeated at least three times about the COVID-19 vaccine. The words represented by the larger circle size are relatively more common. Lines connecting words are indicative of keywords that are together. There are relatively more words represented by larger circle size or font size.

ric analyses. When the Pubmed database was examined, it was found that there were 173 COVID-19 related bibliometric analyzes. Only five of them used the WOS database (12-17). We used the WOS database, too, as it has the highest quality indexing journals.

A bibliometric analysis study, which was examined the publications on COVID-19, conducted by Oliveira et al. (12) in the early pandemic (publications up to May 11, 2020, have been reviewed), determined that most of the publications were made from China. However, we determined that most of the publications were made from the USA. Similar to our results, in the study conducted by Wang et al. (13), most publications were made from the USA. This situation can be attributed to the fact that the pandemic had started in China, but the number of cases decreased rapidly there, and then the
USA became the country with the highest number of cases. Our study supports this result; although the first research and published literature had been from China, China later ranked fourth in the countries' ranking. USA, England, and India were the most productive countries. Most of the publications in previous studies were reviews and letters to editors, but in our study conducted in 2021, most of the publications were found to be articles (12-16).

The Lancet, Journal of Medical Virology and British Medical Journal (BMJ) were the most cited journals in previous studies (12-16). However, according to our study, Vaccine, The Lancet, and The New England Journal of Medicine journals had the most citations. This can result from their being globally high-impact journals and having open calls for articles on the COVID-19 vaccine topic. 


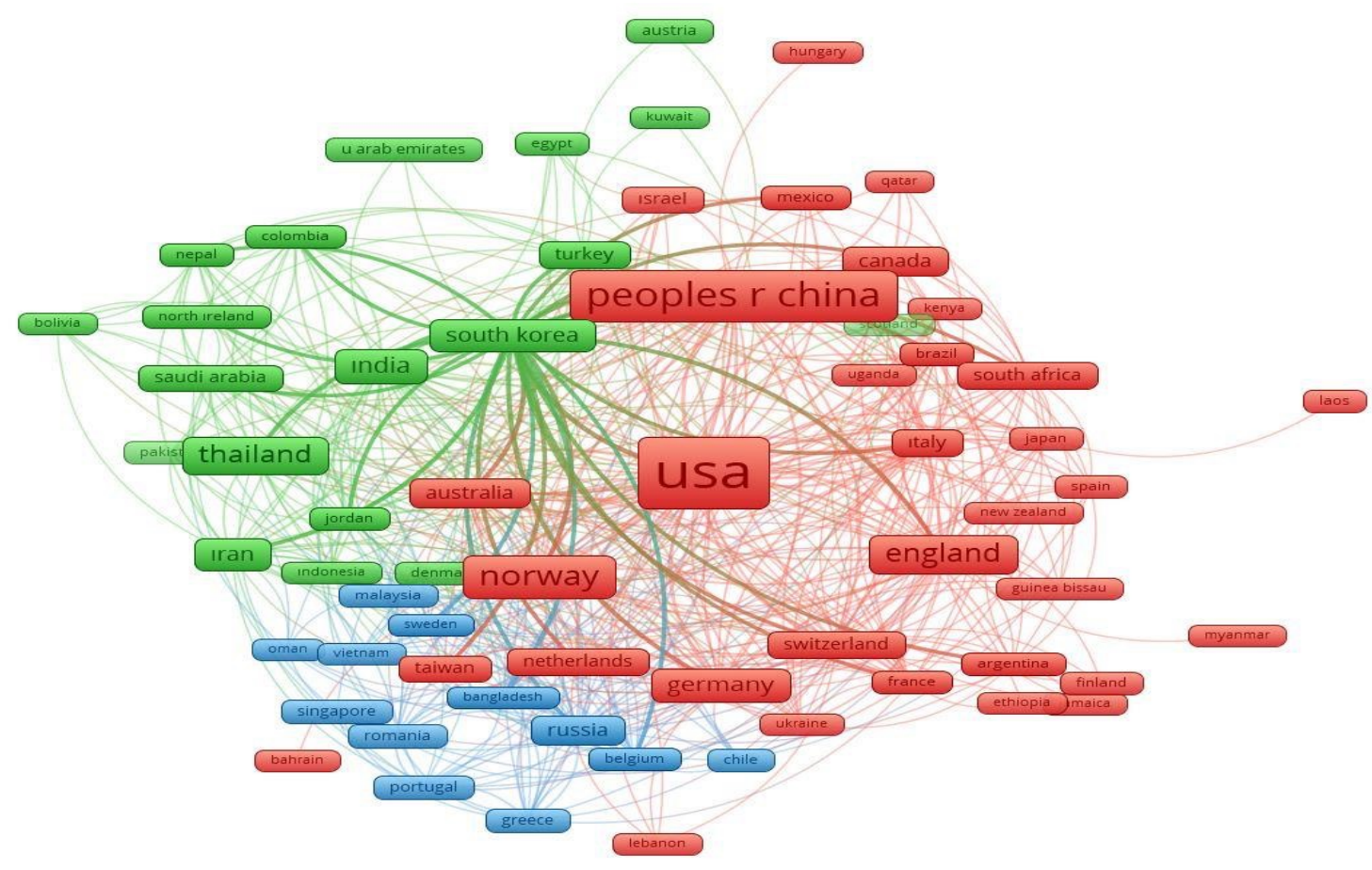

Figure 2. Citation map by countries. Fifty-three countries out of 72 have at least one reference. The number of those who referred to each other is 46.

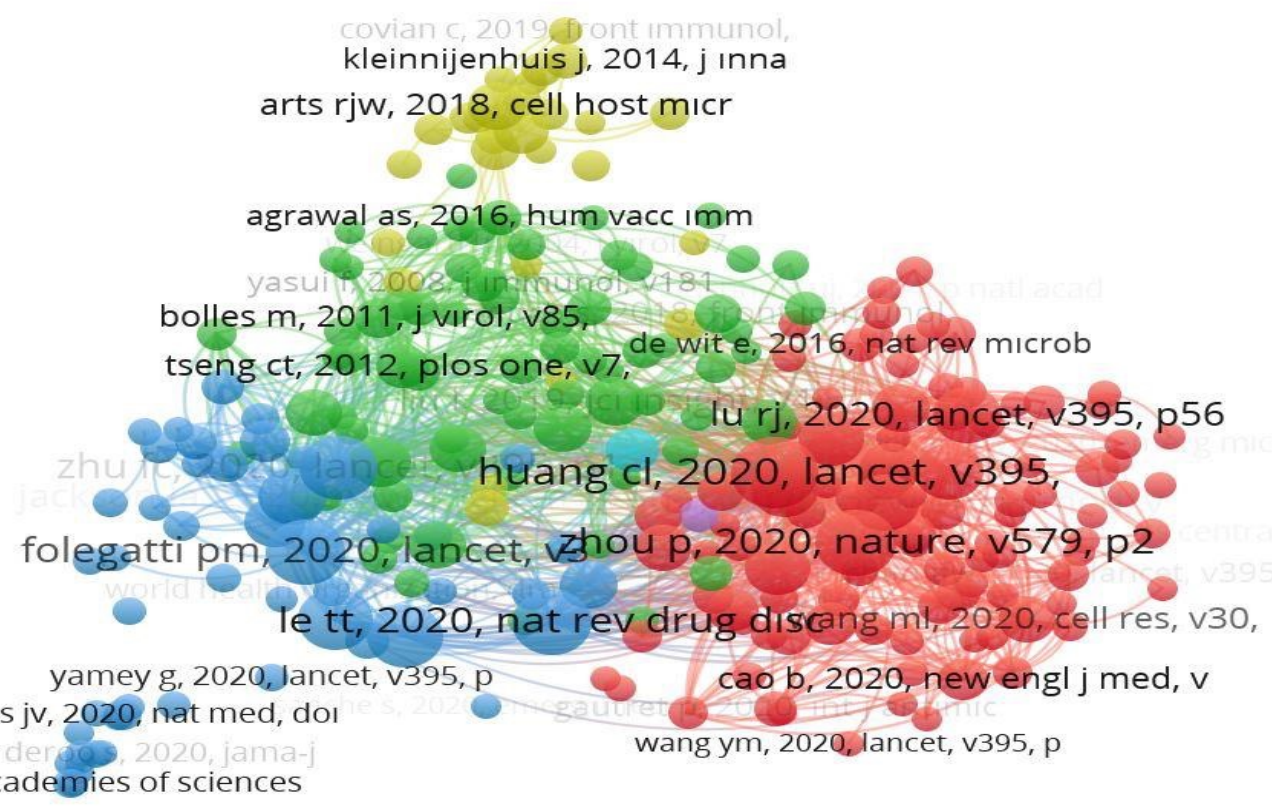

Figure 3. Co-citation map of publications on COVID-19 vaccine by references. 


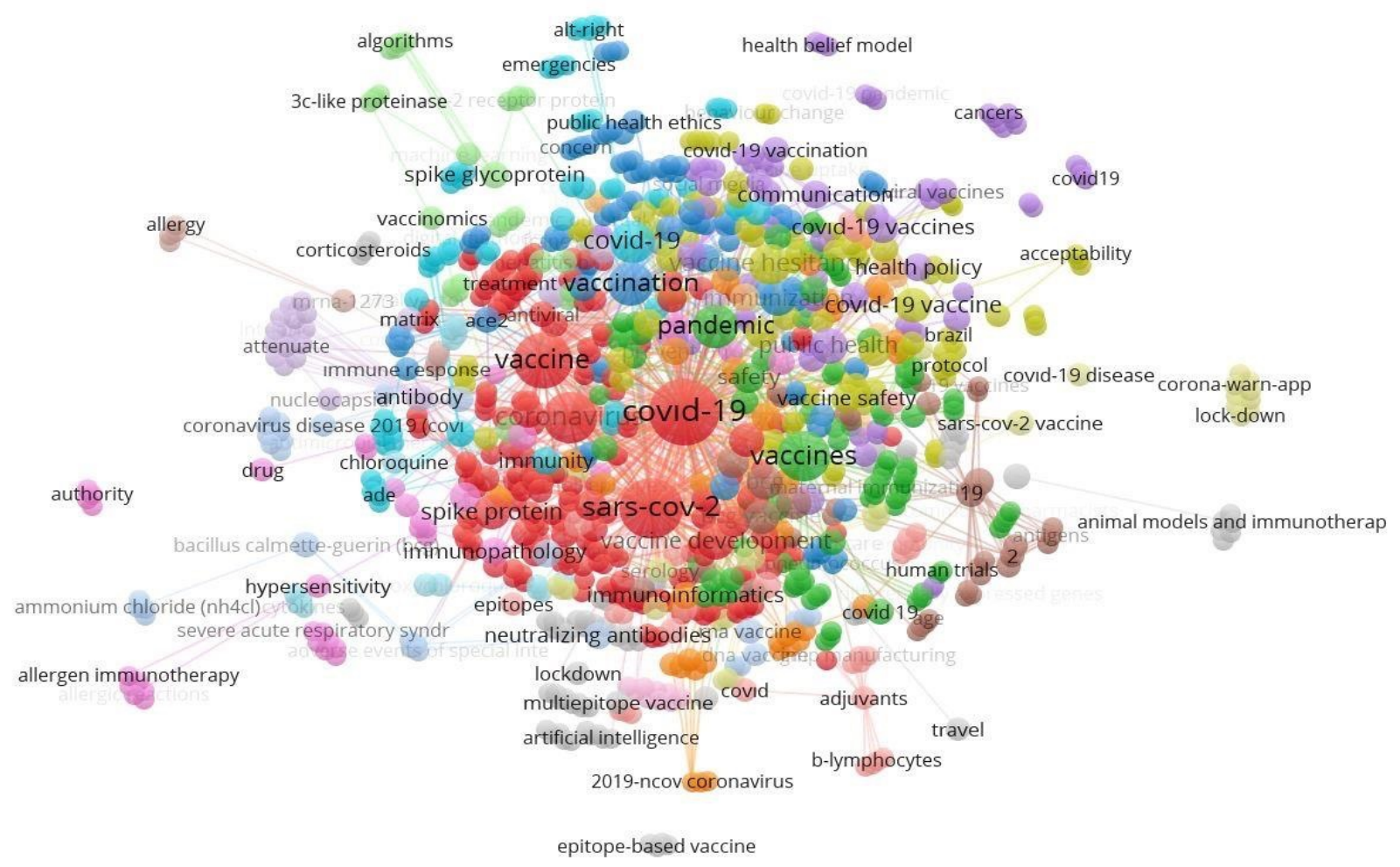

Figure 4. Co-citation map of publications on COVID-19 vaccine by keywords.

General Internal Medicine, Immunology, and Research Experimental Medicine were the most common research areas, and a similar trend was observed in WOS categories.

With 5345 citations in WOS, the WHO had the greatest within the published papers. Since the institution is expected to provide the most accurate and general information about COVID-19 infection and vaccines globally, the number of citations to be so high was accepted as normal.

Furthermore, visualization mapping shows that COVID-19 and the SARS-CoV-2 was the most co-occurrence author keyword. Although significant progress had been made in vaccine development, challenges remained. There were still uncertainties about the effectiveness of the vaccines. This situation was reflected especially in scientific studies. There were thousands of documents on COVID-19 and around ten thousand publications on the COVID-19 vaccine.
Before conducting this study, we conducted a literature review on COVID-19 and bibliometric analysis and included 170 articles. Ahmad et al. (16) conducted a similar study in January 2021; they used the WOS database, also HistCite TM and VOSviewer for visualization. Nine hundred sixteen documents were evaluated. After that study, which was conducted about one month before our study, nine more articles were added to the literature. In that study, Human Vaccines \& Immunotherapeutics was the top-cited journal, but it was Vaccine journal in our study. This situation showed that the studies on COVID-19 and vaccines were rapidly changing. Over time number of papers on the COVID-19 vaccine has been increased.

Our study evaluated the global research trend in the COVID-19 vaccine and provided detailed information about published literature on the COVID-19 vaccine, in addition to constructing visualization network mapping for co-authorship and country, co-occurrence and author keywords, and co-citation and cited sources. 
The current study has several limitations. Because studies in journals that were not scanned in the WOS index could not be evaluated and analyzed. Keywords were only in English, so publications written in other languages might be omitted. Other databases (i.e., Scopus) were not included in the research. Analyses were made only by the VOSviewer. Other software (i.e., CiteSpace II and BibExcel) can be used in future studies.

\section{Ethical Approval: N.A.}

Informed Consent: N.A.

Peer-review: Externally peer-reviewed

Author Contributions: Concept - S.A.; Design - S.A., H.Ö., I.D.A.; Supervision - S.A., H.Ö., D.S.; Materials - S.A.; Data Collection and/ or Processing - S.A., I.D.A.; Analysis and/or Interpretation - D.S.;
Literature Review - S.A., H.Ö.; Writer - S.A., H.Ö., D.S.; Critical Reviews - I.D.A.

Conflict of Interest: The authors have no conflict of interest to declare.

Financial Disclosure: The authors declared that this study has received no financial support.

\section{REFERENCES}

1 Dindar-Demiray EK, Alkan-Çeviker S. Aşı ve toplumsal korunma. J Biotechnol \& Strategic Health Res. 2020;4:37-44. Turkish. [CrossRef]

2 Aytekin E. Salgından çıkışın umudu Kovid-19 aşıları dünyada uygulanmaya başlandı [Internet]. AA Haber. (December 30, 2020; cited April 10, 2021). Turkish. Available from: https:// www.aa.com.tr/tr/dunya/salgindan-cikisin-umudu-kovid-19-asilari-dunyada-uygulanmaya-basladi/2093271

3 Grenfell R, Drew T. Here's why it's taking so long to develop a vaccine for the new coronavirus [Internet]. ScienceAlert. (February 17, 2020; cited April 8, 2021). Available from: https:// www.sciencealert.com/who-says-a-coronavirus-vaccine-is18-months-away

4 Zhao J, Zhao S, Ou J, Zhang J, Lan W, Guan W, et al. COVID-19: Coronavirus vaccine development updates. Front Immunol. 2020;11:602256. [CrossRef]

5 COVID-19 treatment and vaccine tracker [Internet]. Milken Institute FasterCures. (updated October 14, 2021; cited April 8, 2021). Available from: https://covid-19tracker.milkeninstitute.org/

6 Clarivate Analytics. Web of Science Core Collection. (cited April 8, 2021) Available from: https://clarivate.com/webofsciencegroup/solutions/web-of-science-core-collection/

7 Aggarwal A, Lewison G, Idir S, Peters M, Aldige C, Boerckel W, et al. The state of lung cancer research: A global analysis. J Thorac Oncol. 2016;11(7):1040-50. [CrossRef]

8 Xie L, Chen Z, Wang H, Zheng C, Jiang J. Bibliometric and visualized analysis of scientific publications on atlantoaxial spine surgery based on Web of Science and VOSviewer. World Neurosurg. 2020;137:435-42. [CrossRef]

9 Huang T, Wu H, Yang S, Su B, Tang K, Quan Z, et al. Global trends of researches on sacral fracture surgery: A bibliometric study based on VOSviewer. Spine (Phila Pa 1976). 2020;45(12):E721-E8. [CrossRef]
10 Bornmann L, Daniel HD. The state of $h$ index research. Is the $h$ index the ideal way to measure research performance? EMBO Rep. 2009;10(1):2-6. [CrossRef]

11 Mao X, Guo L, Fu P, Xiang C. The status and trends of coronavirus research: A global bibliometric and visualized analysis. Medicine (Baltimore). 2020;99(22):e20137. [CrossRef]

12 Oliveira E, Carvalho A, Silva J, Sousa Neto AR, Moura M, Freitas D. Analysis of scientific production on the new coronavirus (COVID-19): A bibliometric analysis. Sao Paulo Med J. 2021;139(1):3-9. [CrossRef]

13 Wang P, Tian D. Bibliometric analysis of global scientific research on COVID-19. J Biosaf Biosecur. 2021;3(1):4-9. [CrossRef]

14 Shamsi A, Mansourzadeh MJ, Ghazbani A, Khalagi K, Fahimfar N, Ostovar A. Contribution of Iran in COVID-19 studies: A bibliometrics analysis. J Diabetes Metab Disord. 2020;19(2):1-10. [CrossRef]

15 Furstenau LB, Rabaioli B, Sott MK, Cossul D, Bender MS, Farina EMJM, et al. A bibliometric network analysis of coronavirus during the first eight months of COVID-19 in 2020. Int J Environ Res Public Health. 2021;18(3):952. [CrossRef]

16 Ahmad T, Murad MA, Baig M, Hui J. Research trends in COVID-19 vaccine: A bibliometric analysis. Hum Vaccin Immunother. 2021:1-6. [Epub ahead of print] [CrossRef]

17 Malik AA, Butt NS, Bashir MA, Gilani SA. A scientometric analysis on coronaviruses research (1900-2020): Time for a continuous, cooperative and global approach. J Infect Public Health. 2021;14(3):311-9. [CrossRef] 